\title{
CARACTERÍSTICAS PSICOSSOCIAIS DO CONTATO INICIAL COM
} ALUNOS COM DEFICIÊNCIA

\author{
CARACTERÍSTICAS PSICOSOCIALES DEL CONTACTO INICIAL CON \\ ALUMNOS CON DEFICIENCIA \\ PSYCHOSOCIAL CHARACTERISTICS OF THE INITIAL CONTACT WITH \\ STUDENTS WITH DISABILITIES
}

\author{
Maria Nivalda de Carvalho-Freitas, Andrea Carmen Guimarães Giselle Barreto Diniz Rocha, \\ Jéssica Faria Souto e Larissa Medeiros Marinho dos Santos \\ Universidade Federal de São João del-Rei, São João del-Rei/MG, Brasil
}

\section{RESUMO}

Este estudo teve por objetivo identificar as características psicossociais do processo de formação de professores, especificamente do contato inicial com práticas de ensino junto a alunos com deficiência. Participaram da pesquisa 70 universitários de licenciatura de Educação Física. Foram realizadas observações, entrevistas em grupo e análise documental. A partir da análise de conteúdo, os dados indicaram três características psicossociais desse processo: atribuição de origem social às dificuldades vivenciadas na relação; presença de forte mobilização subjetiva; e necessidade de mediação para lidar com a percepção de desequilíbrio entre o conhecimento prévio e a realidade de trabalho. A pesquisa revelou a necessidade de os universitários discutirem a questão da deficiência e deslocarem sua percepção para as possibilidades dos alunos com deficiência. Além disso, os resultados mostram que os professores, o próprio aluno com deficiência e o conhecimento produzido são imprescindíveis na mediação entre o universitário e a atividade pedagógica a ser desenvolvida.

Palavras-chave: educação especial; alunos com deficiência; formação de professores.

\section{RESUMEN}

Ese estudio tuvo por objetivo identificar las características psicosociales del proceso de formación de los profesores, específicamente del contacto inicial con alumnos con deficiencia. Participaron 70 universitarios de Licenciatura en Educación Física. Fueron realizadas observaciones, entrevistas en grupo y análisis documental. A partir de la análisis del contenido, los datos indicaron tres características psicosociales de ese proceso: atribución de origen social a las dificultades vividas en la relación; presencia de fuerte movilización subjetiva y necesidad de mediación para lidiar con la percepción del desequilibrio entre el conocimiento previo y la realidad del trabajo. La pesquisa reveló la necesidad de los universitarios discutieren la cuestión de la deficiencia y cambiaren su percepción para las posibilidades de los alumnos con deficiencia. Además, los resultados muestran que los profesores, el proprio alumno con deficiencia y el conocimiento producido son imprescindibles en la mediación entre el universitario y la actividad pedagógica a ser desarrollada.

Palabras clave: educación especial; alumnos con deficiencia; formación de profesores.

\begin{abstract}
This research aimed to identify the psychosocial characteristics of the process of teacher education, specifically the initial contact with teaching practices with students with disabilities. Participants were 70 undergraduate students of Physical Education. It was used observation, group interviews and documental analyses. From content analyses, the data indicated three psychosocial characteristics of this process: attribution of social origin for the difficulties experienced in the relationship; presence of strong subjective mobilization, and need for mediation to deal with perception of imbalance between prior knowledge and the reality of work. The study revealed the need for future teachers to discuss the issue of disability and shift their perceptions from difficulty to the possibilities of disabled students. The results indicate the essential role of all, teachers, the student with disabilities and the knowledge produced in mediating between the undergraduate students and pedagogical activity to be developed.
\end{abstract}

Keywords: special education, students with disabilities, teacher training. 


\section{Introdução}

O cenário político da educação especial no Brasil, nos últimos 20 anos, passou por várias reformas com implicações práticas no cotidiano das escolas (Garcia \& Michels, 2011). A educação especial, que era objeto, principalmente, das instituições especializadas (Ministério da Educação e Secretaria de Educação Especial, 1994), começa a ser considerada uma modalidade de ensino destinada aos alunos com necessidades educacionais especiais, preferencialmente, na rede regular de ensino (Lei n. 9.394, de 1996), sendo posteriormente enfatizado, por meio da Resolução CNE/CEB n. 2, (2001), seu direcionamento para a rede regular de ensino e, apenas extraordinariamente, o atendimento de alunos com deficiência em escolas ou classes especiais, incorporando, assim, na política nacional, as premissas internacionais sobre a educação especial (Garcia \& Michels, 2011).

Nesse sentido, um conjunto de ações visando à efetivação da Educação Inclusiva na rede regular de ensino vem sendo desenvolvido pelo Ministério da Educação (MEC), por meio da Secretaria de Educação Especial (SEESP), por exemplo: Programa de Implantação de Salas de Recursos Multifuncionais, adequação de prédios escolares para acessibilidade, Formação Continuada de Professores na Educação Especial, além do Programa Educação Inclusiva (MEC \& SEESP, 2012). Tais ações têm buscado garantir condições de acessibilidade física, pedagógica e tecnológica às diferentes necessidades educacionais especiais, para que alunos com deficiência tenham garantidos acesso e permanência nas escolas, com possibilidades reais de socialização e desenvolvimento acadêmico.

Essas mudanças das políticas de educação especial e a implementação de ações de busca de consolidação da Educação Inclusiva no país estão se refletindo no aumento crescente de matrículas na rede regular de ensino que, em 1998, tinha $13 \%$ e, em 2012, 76\% dos alunos com deficiência (SECADI/SESu, 2013). São dados que permitem identificar uma migração explícita dos alunos das escolas especializadas e classes especiais para as classes comuns das escolas regulares. No entanto, ainda que as políticas e ações internacionais e nacionais estejam trabalhando em prol de uma educação inclusiva, as pesquisas têm reiteradamente identificado dificuldades tanto na formação dos professores, inicial e continuada, quanto na atitude social dos educadores frente à inclusão.

No Relatório Mundial sobre a Deficiência (WHO, 2011), foi observada a atitude dos professores como uma das principais barreiras apresentadas para o reconhecimento do direito das pessoas com deficiência terem acesso à educação regular. As explicações para as referidas atitudes foram a formação e/ou a ausência de suporte das escolas de muitos deles.

Glat e Pletsch (2010) detectaram como principal barreira para a inclusão escolar o despreparo dos professores e demais agentes escolares. Por outro lado, os resultados de pesquisa de Nunes, Ferreira e Mendes (1999), Michels (2005) e Huang e Diamond (2009), apontam que, nos cursos de formação de professores para a educação especial, a base principal é a orientação médico-psicológica, assentada em aspectos biológicos e da funcionalidade da pessoa com deficiência, e criticam os limites desses modelos.

Avramidis e Norwich (2002), ao exibirem uma extensa revisão da literatura internacional sobre atitudes dos professores frente à inclusão, também constataram que a natureza da deficiência e o contexto escolar são fatores que influenciam a atitude dos professores. Além das variáveis atribuídas às crianças, variáveis relacionadas ao professor, como tempo de experiência, formação e crenças acerca da deficiência, foram identificadas pelas pesquisas analisadas como fatores que influenciam a atitude dos professores, embora nenhum fator, sozinho, possa ser considerado um forte preditor de suas atitudes. Ademais, pesquisas nacionais relevam a percepção dos professores de falta de preparo para a inclusão de alunos com deficiência (Glat \& Pletsch, 2010; Glat, Plestsch, \& Fontes, 2007; Jesus, Barreto, \& Gonçalves, 2011; Santos, 2002; Vitaliano, 2002, 2007) e sugerem como prioritário o incentivo dos gestores públicos à formação dos professores, tanto na formação inicial quanto na continuada, como uma ação com possibilidade de impacto na atitude dos professores (Aguiar \& Duarte, 2005; Avramidis \& Norwich, 2002; Glat \& Pletsch, 2010; Glat et al., 2007; Melo \& Ferreira, 2009; Melo \& Martins, 2007; Vitta, De Vitta \& Monteiro, 2010 WHO, 2011).

Se, por um lado, existe consenso quanto à importância da formação inicial e continuada dos professores para o trabalho com alunos com deficiência, por outro, uma característica identificada no trabalho com pessoas com deficiência é a mobilização de emoções e sentimentos. Rodrigues (2004) relatou a reação de embaraço de um professor frente a alunos com deficiências motoras em suas aulas; Glat (1995) falou do desconforto e da mobilização de sentimentos de fragilidade quando em contato com pessoas com deficiência. Anjos, Andrade e Pereira (2009) descreveram os sentimentos positivos, negativos, de crise e de transição experimentados pelos professores 
em relação ao processo de inclusão. Vaughn, Schumm, Jallad, Slusher e Saumell (1996) verificaram que a maioria dos professores que não participavam de programas inclusivos tinha fortes sentimentos negativos em relação à inclusão e achava que os proponentes de programas inclusivos não tinham contato com a realidade das salas de aula.

Por outro lado, Villa, Thousand, Meyers e Nevin (1996), em pesquisa de campo, notaram que o comprometimento dos professores no que tange à inclusão de alunos com necessidades educacionais especiais aparecia no final da implementação das ações inclusivas depois que os professores obtinham expertise na condução das atividades. Além disso, pesquisas internacionais indicam que professores mais jovens e com menos anos de experiência têm atitudes mais positivas com respeito à inclusão (Avramidis \& Norwich, 2002). Omote e Pereira Júnior (2011) também verificaram, em pesquisa realizada com professores de um município do Paraná, que professores mais jovens tendiam a ter atitudes mais favoráveis quanto à inclusão do que os mais velhos.

A presente pesquisa foi realizada considerando a regulamentação da educação de pessoas com deficiência nas escolas regulares, as críticas ao processo de formação dos professores, a mobilização de sentimentos dos professores em relação à inclusão e as indicações de que professores mais jovens tendem a ser mais favoráveis à inclusão. Seu objetivo foi identificar as características psicossociais do contato inicial de professores com práticas de ensino junto a alunos com deficiência.

Entende-se por características psicossociais, para efeitos desta pesquisa, os pensamentos, sentimentos e ações que aparecem mais intensamente nas relações. Acredita-se que identificar essas características presentes no contato inicial com pessoas com deficiência pode auxiliar na construção de estratégias de formação de professores, que possam vir a minimizar as desvantagens dos alunos com deficiência em processo de escolarização.

\section{Método}

\section{Participantes}

Participaram da pesquisa 70 alunos de licenciatura de Educação Física - denominados de universitários -, sendo 35 homens e 35 mulheres. Os alunos concordaram em participar da pesquisa e assinaram o Termo de Consentimento Livre e Esclarecido. Trinta universitários participaram da turma do primeiro semestre e quarenta, da turma do segundo semestre. Do total de universitários, $67 \%$ deles estavam na faixa etária dos 21 aos 30 anos, 17\% até 20 anos, 7\% estavam entre 31 e 40 anos, e $7 \%$ entre 41 e 50 anos. Noventa por cento dos universitários declararam-se solteiros e 5,7\%, casados.

No que concerne às informações acerca das deficiências e das pessoas com deficiência, a maioria $(45,6 \%)$ tinha informações superficiais a respeito, $34,3 \%$ já estudaram sobre a inclusão social, 17,1\% já estudaram sobre questões relacionadas à deficiência e $1,4 \%$ não tinham nenhuma informação. Dos universitários, 55,7\% não possuíam informações sobre materiais adaptados que facilitam o trabalho com pessoas com deficiência, $40 \%$ conheciam algum tipo de material e 4,3\% não responderam. Dos participantes da pesquisa, $86,2 \%$ dos alunos de licenciatura do primeiro semestre e 79,3\% do segundo semestre nunca haviam tido contato com pessoas com deficiência; e nenhum dos universitários havia atuado profissionalmente com alunos com deficiência em estágios ou experiências de trabalho anteriores.

Os universitários eram alunos da disciplina Educação Física Adaptada. É uma disciplina obrigatória dentro da grade curricular do curso de licenciatura em Educação Física da universidade pesquisada, com uma carga horária total de 60 horas dividida em teoria e prática. São destinadas 20 horas/ aula para as atividades teóricas e 40 horas para as atividades práticas. A atividade prática foi realizada em uma unidade da Associação de Pais e Amigos dos Excepcionais (APAE). Os universitários foram divididos em grupos para a realização das atividades práticas.

\section{Instrumentos e procedimentos para a coleta de dados}

Foram efetuadas observações livres de todas as aulas teóricas e práticas, durante dois semestres letivos. Nessas observações, era anotado principalmente o comportamento dos alunos frente aos temas discutidos e em relação aos alunos da APAE. Também foram efetuadas 24 entrevistas coletivas com os universitários, com duração média de 30 minutos cada uma, sempre após a execução da última atividade prática semanal realizada junto aos alunos da APAE.

As entrevistas coletivas foram feitas com grupos de dez a quinze universitários. Os temas discutidos em todas as entrevistas foram as emoções e os sentimentos dos universitários perante o contato com alunos com deficiência naquela semana, os pensamentos que lhes ocorriam e as ações ou comportamentos que adotaram 
diante das dificuldades que encontraram. As entrevistas coletivas foram registradas por dois pesquisadores. Os dados coletados eram confrontados para verificar a concordância entre os registros dos pesquisadores e apresentados aos universitários para a validação das suas falas. Conforme Kramer (2003), as entrevistas coletivas, além de permitirem a identificação do ponto de vista dos entrevistados, auxiliam no reconhecimento de aspectos polêmicos e na identificação de conflitos, facilitando o aparecimento de ideias divergentes ou posições antagônicas frente ao conteúdo discutido.

Ademais, o professor da disciplina requisitava aos alunos um relato escrito sobre sua participação durante as intervenções na APAE, que também foi utilizado como dado de pesquisa. Segundo Lüdke e André (1986), a análise documental pode se constituir numa fonte complementar às informações obtidas ou trazer elementos novos para a pesquisa, sendo considerado documento qualquer material escrito que possa ser utilizado como fonte de informação.

\section{Procedimentos de análise}

As observações e as entrevistas coletivas registradas e validadas pelos universitários foram lidas diversas vezes pelos pesquisadores, visando a agrupar e a classificar os dados em categorias temáticas (Bardin, 1994) que refletissem as principais emoções, pensamentos e ações dos universitários frente ao contato inicial com alunos com deficiência. Além disso, o relato mensal de todos os alunos foi digitado e, por meio da utilização de software de análise de conteúdo, foram analisadas as coocorrências de emoções, pensamentos e ações entre uma mesma unidade de contexto (relato mensal). De acordo com Minayo (2005), esse procedimento de análise de coocorrências auxilia a identificação de aspectos latentes nas falas e nos textos.

Foram detectadas três principais características psicossociais da relação dos universitários com alunos com deficiência, que se repetiram, como categorias temáticas, nas duas turmas: atribuição de origem social às dificuldades vivenciadas na relação; presença de forte mobilização subjetiva no contato inicial com a deficiência; e necessidade de mediação para lidar com a percepção de desequilíbrio entre o conhecimento prévio e a realidade de trabalho.

\section{Resultados e discussão}

Os resultados e a discussão serão apresentados, a seguir, conforme as características principais identificadas no decorrer do contato entre os universitários e os alunos com deficiência.
Atribuição de origem social às dificuldades vivenciadas na relação

Dos participantes da pesquisa, $86,2 \%$ dos alunos de licenciatura do primeiro semestre e 79,3\% do segundo semestre nunca haviam tido contato com pessoas com deficiência, o que reafirma a baixa inserção de tais pessoas nas escolas regulares, fenômeno recente na realidade nacional, e a segregação delas dos diversos espaços sociais, dificultando a possibilidade de convivência com a diversidade (Sassaki, 1997), o que contrasta com o contingente de pessoas com deficiência no país, em torno de $23,9 \%$ da população brasileira (IBGE, 2010). Essa mesma realidade também foi vista em pesquisas anteriores (Melo \& Martins, 2007; Reganhan \& Braccialli, 2008). Fichten, Schipper e Cutler (2005) apontaram que interações limitadas entre pessoas com e sem deficiência podem contribuir para aumentar as atitudes negativas devido ao reforço do estereótipo preexistente, percepções negativas e falta de conhecimento em relação às pessoas com deficiência.

Analisando as falas dos universitários, verificase que, quando eles contam que não tiveram contato anterior com pessoas com deficiência, é para justificar as principais dificuldades sentidas nesse processo inicial: $59 \%$ dos alunos de licenciatura disseram que nunca tiveram contato com pessoas com deficiência e que por isso não sabiam como agir, a forma de falar, nem como orientar as referidas pessoas; e $52 \%$ afirmavam que, também por esse motivo, não conheciam os limites das pessoas com deficiência, não sabiam como avaliar sua capacidade de aprendizagem e seu desenvolvimento.

Também associavam sentimentos à falta de contato prévio com pessoas com deficiência, a predominância foi dos sentimentos de ansiedade (96\%) e insegurança inicial (58,6\%). As falas a seguir ilustram as análises: "Nunca tive o contado com pessoas com deficiência. Não sei o que fazer. A gente tenta fugir um pouco das situações por não saber o que fazer" (Aluna M). "Estou insegura, não sei o que fazer. É a primeira vez que tenho contato com pessoas com deficiência" (Aluna R). "Me senti mal, estou suando até agora. Foi um desafio para mim, porque eu nunca tive contato com pessoas deficientes. Não sei como chamá-los, não sei como lidar com pessoas deficientes, foi muito difícil para mim” (Aluno M).

Nas observações dos primeiros contatos dos universitários com os alunos com deficiência, notouse que, nas atividades realizadas, por exemplo: dar as mãos para fazer rodas, os universitários ficavam todos juntos, de um lado da roda, e os alunos com 
deficiência juntos, do outro lado da mesma roda. Além disso, alguns alunos de licenciatura só entravam na APAE quando a professora ou monitora da disciplina chegava.

Allport (1954) já afirmava que o contato social com pessoas com deficiência poderia promover visões mais positivas dessas pessoas, minimizando as atitudes negativas, sobretudo se acompanhado de status igual, cooperação, sanção da comunidade perante as atitudes negativas e maior proximidade com elas.

Ishige e Hayashi (2005) enfatizaram que a qualidade e a quantidade de contato com pessoas com deficiência têm impacto na atitude frente a tais pessoas. A possibilidade de contato prévio e a qualidade desse contato são fatores que as pesquisas identificam como tendo influência no desenvolvimento de atitudes mais favoráveis em relação às pessoas com deficiência. Também Omote e Pereira Júnior (2011) verificaram que professores que tinham alguma experiência docente prévia com alunos com deficiência possuiam uma atitude social significativamente mais favorável à inclusão que os demais professores.

A falta de oportunidade de convivência com as referidas pessoas explicita o que Hughes (2012) denomina de expressão de um processo civilizatório, em que a sociedade tende a manter as pessoas com deficiência em espaços segregados ou a tentar torná-las as mais idênticas possíveis às pessoas sem deficiência. Tal segregação transforma o contato inicial com as pessoas com deficiência em um processo permeado de insegurança e ansiedade frente a uma realidade desconhecida, sublinhando a origem social desses processos. Pichón-Rivière (1988) afirma que, diante de uma realidade desconhecida, é comum a sensação de desestruturação, a ansiedade, a confusão e a incerteza. Segundo Hughes (2012), o medo, na presença da deficiência, é, em parte, medo da precariedade própria do ser humano e de sua vulnerabilidade perante a vida, e implica ameaça. Conforme o mencionado pesquisador, a sociedade é a responsável por esse sentimento, pois coloca a deficiência fora dos olhos e fora dos pensamentos das pessoas quando as segrega em espaços separados.

\section{Presença de forte mobilização subjetiva no contato inicial com a deficiência}

Embora a principal origem dos sentimentos experimentados em relação às pessoas com deficiência possa ser atribuída à ausência de contato anterior, o contato inicial com essas pessoas se caracteriza pela presença de intensa mobilização interna do sujeito, trazendo à tona diversas emoções relacionadas à própria existência e à fragilidade humana. Todos os universitários explicitaram que sentiram a presença de emoções e sentimentos variados no contato com alunos com deficiência, que eram diferentes e mais intensos do que de outras experiências de prática docente.

Analisandoas falas dosuniversitários relacionadas aos sentimentos e às emoções experimentados em relação aos alunos com deficiência, verificou-se que a piedade e a compaixão apareceram entre $11 \%$ dos alunos do primeiro semestre e entre $17 \%$ dos alunos do segundo semestre. Esses sentimentos estavam associados principalmente à percepção de fragilidade atribuída às pessoas com deficiência: "Tive vontade de chorar, fiquei com pena dos alunos. A gente repensa os valores da vida" (Aluna G). "A gente fica com pena, a sensação que dá é que são bonecos de porcelana, que são frágeis e que precisamos cuidar, dar carinho $e$ proteger" (Aluna $\mathrm{H})$.

Hughes (2012) afirma que a piedade é uma emoção que hierarquiza as pessoas, sendo a superioridade relacionada àqueles que sentem e a inferioridade, ao status projetado naqueles que são seu alvo. As pessoas com deficiência são vistas como infortunadas e objeto de grande sofrimento. A elas, são destinadas a simpatia e a caridade, fruto de uma moral religiosa. No entanto, no mundo real, as pessoas comparam a si mesmas com os outros e, nesse contexto, a busca de dominação de uns sobre os outros transforma a piedade de um estado de natural simpatia e compaixão em um sintoma base da desigualdade social. A assertiva de Hughes (2012) pode ser vista na concretização das ações sociais frente às pessoas com deficiência quando, quase nunca, elas são ouvidas sobre suas próprias necessidades. As pessoas sem deficiência, os profissionais, em geral, definem o que é mais adequado na ausência da participação delas. Perguntas simples não são feitas, por exemplo: como você acha mais fácil pegar no lápis para escrever? Como você faz uma determinada atividade no seu dia a dia? A caridade, de acordo com Hughes (2012), requer uma classe de pessoas definidas como necessitadas, como socialmente inválidas.

Durante a pesquisa, cerca de $10 \%$ dos universitários associavam o trabalho com pessoas com deficiência mais a uma missão que a uma profissão: "Para trabalhar com essas pessoas, é preciso ter dom. Não é para qualquer pessoa" (Aluno D). Tal atribuição de missão à atividade de trabalho com pessoas com deficiência desobriga aqueles que não se sentem contemplados com esse "dom" a desenvolverem atividades pedagógicas que possam colaborar no desenvolvimento cognitivo e/ou motor dos referidos alunos. 
Outros sentimentos também são mobilizados nesse contato inicial, por exemplo, o nojo/repugnância foi destacado por $10 \%$ dos universitários: "Tenho dificuldade de lidar com a questão do cheiro, se tem uma pessoa com algum cheiro desagradável, meu estômago embrulha e não sei como fazer em certas situações que necessite chegar perto dessa pessoa" (Aluna J2). "Tenho dificuldades em lidar com baba. O que fazer quando um aluno babando quiser me beijar?" (Aluna S). A repugnância também é um sentimento experimentado pelas pessoas, principalmente se algo é percebido como perigoso por causa do poder imputado e percebido de contaminar, infectar ou poluir pela proximidade de contato ou ingestão (Hughes, 2012). Repugnância relacionada à baba e ao escarro é associada historicamente à doença e ao contágio. Segundo Wong, Chan, Cardoso, Lam e Miller (2004), novas experiências e encontros podem evocar ansiedade e influenciar as pessoas a desenvolver mecanismos de defesa, como a evasão e a racionalização, para minimizar os sentimentos, pensamentos e situações que eles percebem como perigoso ou desconfortável. Essas reações na interação de pessoas com e sem deficiência podem, conforme tais pesquisadores, prejudicar o processo de integração das pessoas com deficiência.

Também a reflexão sobre a própria vida se faz presente no contato inicial, sendo que $51,7 \%$ dos universitários relataram questões como: "Tenho tido muita vontade de chorar. Estou me sentindo frágil. Às vezes, tenho vontade de não fazer essa disciplina" (Aluna A).

Esse trabalho com alunos com deficiência me faz pensar sobre minha própria vida. Eu tenho tantas possibilidades e, muitas vezes, não dou valor. A gente evita pensar em coisas ruins, mas aqui não tem jeito, a gente vê que nós estamos sujeitos a muitos problemas e dificuldades. Isso angustia muito. (Aluna L)

A mobilização de emoções e sentimentos no contato com pessoas com deficiência foi identificada por diversos pesquisadores, dentre eles: Rodrigues (2004), Glat (1995) e Anjos, Andrade e Pereira (2009). Solomon, Greenberg e Pyszczynski (1991) afirmam que, dependendo do contexto cultural, as pessoas com deficiência podem ser vistas como ameaças à sua visão de mundo. Para os citados pesquisadores, as pessoas que não se enquadram no padrão cultural ou de valores compartilhados são vistas como ameaça e podem gerar ansiedade, sobretudo se evocam a consciência da morte e da fragilidade humana.

Necessidade de mediação para lidar com a percepção de desequilíbrio entre o conhecimento prévio e a avaliação da realidade de trabalho
Embora a formação teórica tenha sido realizada, o contato dos universitários com pessoas com deficiência em uma atividade de prática de ensino intensificou a sensação de ausência de conhecimento que fosse capaz de auxiliá-los a lidar com a nova realidade que se apresentava. As ações requeridas exigiam que conseguissem articular o que conheciam teoricamente com uma realidade que desconheciam.

$\mathrm{O}$ sentimento de medo, ligado em especial às dificuldades de não saber como agir, como colocar limites e de ter dúvidas se efetivamente poderiam contribuir com essas pessoas, apareceu em $62,1 \%$ dos alunos do primeiro semestre e em $51,7 \%$ entre os do segundo semestre. Algumas falas: "Resumindo, estou em pânico, não sei resumir direito o que estou sentindo. Tenho medo de não saber o que trabalhar e, ao invés de ajudar, atrapalhar. Estou sentindo pânico, medo" (Aluna C). "Fico com medo de não saber o que fazer quando alguém tentar falar e eu não entender. Medo de não suprir as necessidades deles e de relacionar" (Aluna CI). "A gente não sabe como falar, o que fazer, o que é certo ou errado. Onde posso trabalhar ou não. É horrível, a gente não tem controle, não tem segurança de como falar. Fico perdido" (aluno D).

No primeiro momento, é de assustar, apesar de já ter tido algum contato com pessoas com deficiência antes, acredito que alguns podem ser mais fáceis de lidar. $O$ contato foi bom, mas estou inseguro em relação ao trabalho com uma das alunas. A preparação tem que ser bem feita. Estou preocupado e assustado, mas também feliz e animado em conhecê-los melhor. (Aluno G)

A ameaça frente ao novo, comum entre as pessoas (Pichón-Rivière, 1988), é intensificada devido à segregação social, que é histórica entre as pessoas com deficiência e que impede uma convivência cotidiana com elas. Embora a experiência prática da disciplina tenha ocorrido em um contexto no qual os professores da APAE e da disciplina de Educação Física Adaptada estivessem presentes e acompanhando o processo, ainda assim apareceram os sentimentos de dificuldade e impotência. Diante desses sentimentos e da realidade colocada, os universitários adotaram diferentes pautas de conduta. Todos eles, em tempos diferentes, buscaram se aproximar dos alunos com deficiência, observaram a condução das aulas dos colegas, fizeram anotações e discutiram o que acontecia após cada aula ministrada.

Com o decorrer das atividades práticas, foram sendo percebidos aspectos que facilitavam a relação e a avaliação das possibilidades das pessoas com deficiência. Os principais facilitadores identificados foram: contato gradativo com as pessoas com 
deficiência, ajudando a conhecer as dificuldades, possibilidades e expectativas delas $(51,7 \%$ na primeira turma e 44,8\% na segunda turma); observação e conhecimento do trabalho do professor responsável pela turma e a presença do professor da universidade no acompanhamento das aulas ministradas pelos universitários (96,6\% e 91\%); boa receptividade e participação das pessoas com deficiência $(88,6 \%$ e $96,2 \%$ ); e percepção de resultados para as pessoas com deficiência $(20,7 \%$ e $17,2 \%)$.

Quando analisadas as falas dos alunos, foram verificados aspectos que facilitaram a experiência vivida. Notou-se que os universitários associavam as facilidades à identificação de benefícios advindos desse processo, que foram: a possibilidade de repensar valores relacionados à prática pedagógica e em relação às pessoas com deficiência (41,4\% e 48,3\%); a possibilidade de aprender com elas (37,9\% e 37,9\%); a realização de experiências fundamentais para a formação $(58,6 \%$ e 55,2\%); e a aprendizagem de prováveis maneiras de se trabalhar com pessoas com deficiência $(48,3 \%$ e 44,8\%).

Por outro lado, foi identificada a diminuição do medo e da insegurança com o decorrer do contato, sendo que $68,9 \%$ dos alunos do primeiro semestre e $71,4 \%$ dos alunos do segundo semestre, já no final do primeiro mês de prática de ensino, afirmavam estar mais tranquilos junto aos alunos com deficiência. As falas a seguir ilustram tal constatação: "Quanto mais observo as aulas, fico mais tranquilo" (Aluno E). "Você começa a olhar com certa naturalidade com o passar dos dias. A gente aprende com a experiência. A gente vai saber como colocar limite. Com o tempo, você pega o jeito de conversar com todos" (Aluno G).

Os componentes emocionais da relação vão diminuindo de intensidade mediante um processo de adaptação em relação ao diferente, em que o contexto e os comportamentos são observados, e começa-se a identificar possibilidades de ação. É importante sublinhar que a minimização da percepção de desequilíbrio entre o conhecimento prévio e a realidade encontrada só acontece com o enfrentamento dos sentimentos mobilizados por meio da manutenção contínua da relação com os alunos com deficiência. Esse contato é o principal impulsionador das reflexões e do processo de ressignificação da relação. Porém, as consequências de tal relação podem levar a diferentes destinos.

Os principais destinos identificados foram: a adaptação passiva com foco apenas na convivência pacífica, priorizando a socialização das pessoas com deficiência; a divisão dos alunos, tendo por critério os diferentes "desvios" da normalidade; e a busca de um processo de adaptação ativa, em que foram buscadas estratégias de ensino-aprendizagem que pudessem minimizar as desvantagens sociais vivenciadas por esses alunos.

Os universitários que priorizaram a socialização dos alunos com deficiência acreditavam que estavam cumprindo seu papel, pois os alunos estavam "felizes" fazendo atividades juntos. Essa ênfase apenas no processo de socialização desobrigava os universitários a enfrentarem os desafios do processo de ensino-aprendizagem com alunos que traziam necessidades educacionais especiais. Além disso, negava aos referidos alunos a possibilidade de realizar atividades básicas que poderiam contribuir mais efetivamente para o desenvolvimento de uma vida autônoma. A ausência de reflexão e da mediação do conhecimento para o desenvolvimento dos alunos com deficiência tem grande potencial de paralisação dos futuros profissionais e reprodução de preconcepções, do senso comum e da prerrogativa de que apenas a socialização é necessária aos alunos com deficiência. Essa estratégia, que pode ser considerada uma precarização da formação dos alunos, principalmente com deficiência intelectual, é explicitada por Glat e Pletsch (2010) quando discutem o papel da universidade para o desenvolvimento de uma educação inclusiva.

Outra estratégia observada durante o trabalho dos alunos de licenciatura foi a divisão dos alunos com deficiência por tipo de deficiência e grau de desenvolvimento. Os universitários consideravam que a ação de focar a deficiência traria melhor resultado. Essa ação tem por pressuposto a concepção da deficiência como um desvio da normalidade e que é necessário reabilitar tais pessoas para elas serem o mais parecido possível com aquelas consideradas "normais" (Carvalho-Freitas \& Marques, 2007). Os universitários foram, então, estimulados pelos professores a desenvolver as atividades coletivamente, uma vez que em sala de aula trabalhariam com os alunos conjuntamente e nem sempre teriam auxiliares. Verificaram, nas aulas seguintes, que os próprios alunos com deficiência se ajudavam: os que tinham mais facilidade se ofereciam para ajudar aos demais. Além disso, passaram a desenvolver atividades únicas com complexidades diferentes para que todos pudessem participar. Em outras ocasiões, faziam atividades diferenciadas e encerravam a aula com uma atividade coletiva que normalmente os alunos apreciavam muito.

A outra estratégia foi a busca de novos conhecimentos e de ajuda que pudessem auxiliar os universitários a fazer frente às demandas de seus 
alunos. A conversa do professor da universidade com os universitários logo após a aula com os alunos com deficiência foi avaliada como facilitadora, pois permitia aos universitários refletirem sobre a atuação, identificarem os aspectos positivos da aula e as dificuldades, e construírem coletivamente alternativas para lidar com elas. Uma aprendizagem que foi se consolidando consistiu no deslocamento da atenção das limitações para as possibilidades das pessoas com deficiência. Mediante uma dificuldade, discutiam em seguida sobre as potencialidades dessas pessoas e como utilizá-las a favor de novas atividades de ensino. Discutiam também aspectos relacionados ao comportamento das pessoas com deficiência e verificavam que era necessário colocar limites e desafiá-las para um maior desenvolvimento. Também, os universitários pesquisavam e eram estimulados a desenvolver materiais pedagógicos e fazer adaptações nos existentes, a fim de criar novas formas de trabalhar com os alunos e estimulá-los no processo de aprendizagem.

Conforme observado na pesquisa, esse processo de adaptação ativa necessitou ser um processo mediado, com intervenção do conhecimento já produzido no campo, presença do professor e escuta das necessidades dos próprios alunos com deficiência. "Os próprios alunos vão nos mostrando como é mais fácil para eles. Eles também nos ajudam. Ajudam os que têm mais dificuldade" (Aluno H). "Encontramos muitas sugestões na internet. Os professores nos ajudam. Vamos aprendendo a ver diferente e percebemos que esse trabalho dá resultado" (Aluna $\mathrm{G}$ ).

A gente muda. No começo, o que chama a atenção é a deficiência. Depois, vamos aprendendo que é preciso olhar para as potencialidades que podem ajudar a vencer as dificuldades. Vamos vendo que dá certo, que os alunos se desenvolvem. Alguns só conseguiam andar com ajuda, caiam à toa. Agora, estão mais firmes, andam com mais segurança. (Aluno A)

Essa mediação foi o que possibilitou deslocar o olhar da deficiência para as potencialidades; e dos limites, colocados pela deficiência, para as desvantagens oriundas da sociedade que não contempla a diversidade própria do humano. A tendência das pessoas é avaliar o mundo a partir de suas matrizes de referência, isto é, do seu esquema conceitual, referencial e operativo (Pichón-Rivière, 1988). Os resultados da pesquisa indicam que é preciso construir outras referências de análise, para que as ações sejam modificadas. Nesse sentido, a formação dos futuros professores é a matéria-prima essencial para a promoção de uma educação inclusiva. Como as atitudes negativas são difíceis de serem mudadas, os pesquisadores sugerem que "um dos métodos mais eficazes para fazê-lo é fornecer novas informações que desafiam as crenças existentes" (Hunt \& Hunt, 2004, p. 266).

\section{Considerações finais}

A presente pesquisa permitiu identificar características psicossociais presentes no contato inicial de trabalho com alunos com deficiência que foram a constatação da origem social das dificuldades em se lidar com eles, fruto de uma sociedade que segrega tais pessoas; a intensa mobilização subjetiva das pessoas quando se defrontam com a deficiência, trazendo à tona sentimentos, como angústia frente à fragilidade humana e a própria morte, compaixão e repugnância; e a necessidade de mediação diante da percepção de desequilíbrio entre o conhecimento prévio e a realidade de trabalho.

A mediação realizada com o auxílio do conhecimento produzido, dos professores e das próprias pessoas com deficiência se revelou o mais importante alicerce para que os futuros professores pudessem repensar suas ações, deslocar sua percepção da deficiência para as possibilidades das pessoas com deficiência e discutir a questão da deficiência como fruto de uma desvantagem gerada pela atual organização social e do conhecimento. Esse resultado sublinha a relevância estratégica do processo de formação de professores para a construção de uma educação inclusiva, já indicado em inúmeras pesquisas (Avramidis \& Norwich, 2002; Glat \& Pletsch, 2010; Glat et al., 2007; Melo \& Ferreira, 2009; Vitta et al., 2010; ). Todavia, a referida formação precisa considerar a articulação entre pensamento, emoção e ação para produzir mudanças. Os resultados mostraram que tal articulação só será alcançada quando a relação entre o universitário e sua ação pedagógica for mediada por novos conhecimentos e pela presença de professores que auxiliem na reflexão sobre seus sentimentos, dificuldades e estratégias adotadas para lidar com alunos com necessidades educacionais especiais. Também a mediação das próprias pessoas com deficiência que falam de suas necessidades, das estratégias que elas consideram mais fáceis e dos resultados que alcançam é imprescindível nesse processo. Do contrário, podese ter o desenvolvimento de estratégias de adaptação passiva com o foco apenas na socialização e na segregação dos alunos com deficiência nas atividades de sala de aula. Novas pesquisas deverão ser realizadas para verificar se essas características se repetem em outros contextos de formação. 


\section{Referências}

Aguiar, J. S. \& Duarte, É. (2005). Educação inclusiva: um estudo na área da educação física. Revista Brasileira de Educação Especial, 11(2), 223-240.

Allport, G. W. (1954). The nature of prejudice. Cambridge: Addison-Wesley.

Anjos, H. P., Andrade, E. P., \& Pereira, M. R. (2009). A inclusão escolar do ponto de vista dos professores: o processo de constituição de um discurso. Revista Brasileira de Educação, 14(40), 116-129.

Avramidis, E. \& Norwich, B. (2002). Teachers' attitudes towards integration/inclusion: a review of the literature. European Journal of Special Needs Education, 17(2), 129-147.

Bardin, L. (1994). Análise de Conteúdo. Lisboa: Edições 70.

Carvalho-Freitas, M. N. \& Marques, A. L. (2007). A diversidade através da história: a inserção no trabalho de pessoas com deficiência. Organizações \& Sociedade, 14(41), 57-78.

Fichten, C. S., Schipper, F., \& Cutler, N. (2005). Does volunteering with children affect attitudes towards adults with disabilities? A prospective study of unequal contact. Rehabilitation Psychology, 50, 164-173.

Garcia, R. M. C. \& Michels, M. H. (2011). A política de educação especial no Brasil (1991-2011): uma análise da produção do GT15 da Educação Especial da ANPED. Revista Brasileira de Educação Especial, 17, 105-124.

Glat, R. (1995). Integração dos portadores de deficiências: uma questão psicossocial. Temas em Psicologia, 3(2), 89-94.

Glat, R. \& Plesch, M. D. (2010). O papel da universidade no contexto da política de educação inclusiva: reflexões sobre a formação de recursos humanos e a produção de conhecimento. Revista Brasileira de Educação Especial, 23(38), 345-356.

Glat, R., Plesch, M. D., \& Fontes, R. S. (2007). Educação inclusiva \& educação especial: propostas que se complementam no contexto da escola aberta à diversidade. Educação, 32(2), 343-356.

Huang, H. H. \& Diamond, K. E. (2009). Early childhood teachers' ideas about including children with disabilities in programs designed for typically developing children. International Journal of Disability Development and Education, 56, 169-182.

Hughes, B. (2012). Fear, pity and disgust: emotions and the non-disabled imaginary. In N. Watson, A. Roulstone, \& C. Thomas (Orgs.), Routledge Handbook of Disability Studies (pp. 67-77). New York: Taylor and Francis.

Hunt, C. S. \& Hunt, B. (2004). Changing attitudes toward people with disabilities: Experimenting with an educational intervention. Journal of Managerial Issues, 16, 266-280.

Instituto Brasileiro de Geografia e Estatística - IBGE. (2010). Censo 2010. Acesso em 25 novembro, 2012, em http://www. ibge.gov.br/home/estatistica/populacao/censo2010/.

Ishige, N. \& Hayashi, N. (2005). Occupation and social experience: Factors influencing attitude towards people with schizophrenia. Psychiatry and Clinical Neurosciences, 59, 89-95.

Jesus, D. M., Barreto, M. A. S. C., \& Gonçalves, A. F. S. (2011). A formação do professor olhada no/pelo GT-15 - Educação Especial da ANPED: desvelando pistas. Revista Brasileira em Educação Especial, 17, 77-92.

Kramer, S. (2003). Entrevistas coletivas: uma alternativa para lidar com diversidade, hierarquia e poder na pesquisa em ciências humanas. In M. T. Freitas, S. J. Souza, \& S. Kramer
(Orgs.), Ciências Humanas e Pesquisa: leituras de Mikhail Bakhtin (pp. 57-76). São Paulo: Cortez.

Lei n. 9.394, de 20 de dezembro de 1996. (1996). Estabelece as Diretrizes e Bases da Educação Nacional. Brasília, DF: Câmara dos Deputados.

Lüdke, M. \& André, M. E. D. A. (1986). Pesquisa em Educação: abordagens qualitativas. São Paulo: EPU.

Melo, F. R. L. V. \& Martins, L. A. R. (2007). Acolhendo e atuando com alunos que apresentam paralisia cerebral na classe regular: a organização da escola. Revista Brasileira de Educação Especial, 13(1), 111-130.

Melo, F. R. L. V. \& Ferreira, C. C. A (2009). O cuidar do aluno com deficiência física na educação infantil sob a ótica das professoras. Revista Brasileira de Educação Especial, 15 (1), 121-140.

Michels, M. H. (2005). Paradoxos da formação de professores para a Educação Especial: o currículo como expressão da reiteração do modelo médico-psicológico. Revista Brasileira de Educação Especial, 11(2), 255-272.

Minayo, M. C. S. (2005). Introdução: conceito de avaliação por triangulação de métodos. In M. C. S. Minayo, S. G. Assis, \& E. R. Souza (Orgs.), Avaliação por triangulação de métodos: abordagem de programas sociais (pp. 19-51). Rio de Janeiro: Fiocruz.

Ministério da Educação - MEC \& Secretaria de Educação Especial - SEESP. (2012). Apresentação da Secretaria de Educação Especial. Brasília, DF: Ministério da Educação. Acesso em 26 de novembro, 2012, em http://portal.mec. gov.br/index.php?option $=$ com content $\&$ view $=$ article \&id $=288$ : secretaria-de-educacao-especial-\&catid=192: seespesducacao-especial\&Itemid=824.

Nunes, L. R. D. P., Ferreira, J. R., Glat, R., \& Mendes, E. G. (1999). A pós-graduação em Educação Especial no Brasil: análise crítica da produção discente. Revista Brasileira de Educação Especial, 3(5), 113-126.

Omote, S. \& Pereira Jr., A. A. (2011). Atitudes sociais de professoras de um município de médio porte do Paraná em relação à inclusão. Pesquisas e Práticas Psicossociais, 6(1), 7-15.

Pichón-Rivière, E. (1988). O processo grupal. São Paulo: Martins Fontes.

Reganhan, W. G. \& Braccialli, L. M. P. (2008). Inserção de alunos com deficiência no ensino regular: perfil da cidade de Marília. Revista Brasileira de Educação Especial, 14(3), 385-404.

Resolução CNE/CEB n. 2, de 11 de setembro de 2001. (2001). Institui Diretrizes Nacionais para a Educação Especial na Educação Básica. Brasília, DF: Ministério da Educação.

Rodrigues, D. (2004). A Inclusão na Universidade: limites e possibilidades da construção de uma Universidade Inclusiva. Cadernos de Educação Especial, 23. Acesso em 25 novembro, 2012, em http://coralx.ufsm.br/revce/ ceesp/2004/01/a1.htm.

Santos, J. B. (2002). A "dialética da inclusão/exclusão" na história da educação de "alunos com deficiência". Revista da FAEEBA - Educação e Contemporaneidade, 1(1), 27-44.

Sassaki, R. (1997). Inclusão: construindo uma sociedade para todos. Rio de Janeiro: WVA.

Secretaria de Educação Especial - SEESP. (1994). Política nacional de educação especial. Brasília, DF: Ministério da Educação.

Secretaria de Educação Continuada, Alfabetização, Diversidade e Inclusão - SECADI \& Secretaria de Educação Superior - 
SESu. (2013). Documento orientador: Programa Incluir, Acessibilidade na Educação Superior. Brasília, DF: Ministério da Educação.

Solomon, S., Greenberg, J., \& Pyszczynski, T. (1991). A terror management theory of social behavior: the psychological functions of self-esteem and cultural worldviews. In M. P. Zanna (Ed.), Advances in experimental social psychology (pp. 93-159). San Francisco: Academic Press.

Vaughn, J. S., Schumm, J., Jallad, B., Slusher, J., \& Saumell, L. (1996). Teachers' views of inclusion. Learning Disabilities Research and Practice, 11, 96-106.

Villa, R., Thousand, J., Meyers, H., \& Nevin, A. (1996). Teacher and administrator perceptions of heterogeneous education. Exceptional Children, 63, 29-45.

Vitaliano, C. R. (2002). Concepções de professores universitários da área de educação e do ensino regular sobre o processo de integração de alunos especiais e a formação de professores. Tese de Doutorado, Programa de Pós-graduação em Educação, Universidade Estadual Paulista, Marília, SP.

Vitaliano, C. R. (2007). Análise da necessidade de preparação pedagógica de professores de cursos de licenciatura para a inclusão de alunos com necessidades educacionais especiais. Revista Brasileira em Educação Especial, 13(3), 399-414.

Vitta, F. C. F., De Vitta, A., \& Monteiro, A. S. R. (2010). Percepção de professores de educação infantil sobre a inclusão da criança com deficiência. Revista Brasileira de Educação Especial, 16(3), 415-428.

Wong, D. W., Chan, F., Cardoso, E. D., Lam, C. S., \& Miller, S. M. (2004). Rehabilitation counseling students' attitudes toward people with disabilities in three social context: A joint analysis. Rehabilitation Counseling Bulletin, 47, 194204.

World Health Organization - WHO. (2011). World report on disability 2011. Switzerland, 2011. Acesso em 02 fevereiro, 2012 em http://whqlibdoc.who.int/ publications/2011/9789240685215 eng.pdf.

\section{Agradecimento}

Ao CNPq, pelo apoio e financiamento da pesquisa Edital CNPq PQ 2013, Processo 311288/2013-8.

Submissão em: 15/07/2013

Revisão em: 25/03/2014

Aceite em: 21/05/2014

Maria Nivalda de Carvalho-Freitas é professora Adjunta do Departamento e do Mestrado de Psicologia. Psicologia Social e do Trabalho. Endereço: Praça Dom Helvécio, 74

Departamento de Psicologia. Campus Dom Bosco. São João del-Rei, Minas Gerais, Brasil. CEP 36.301-160 E-mail: nivalda@ufsj.edu.br

Andrea Carmen Guimarães é professora Adjunta do Departamento de Educação Física. Educação Física Adaptada. E-mail: andreaguimaraes@ufsj.edu.br

Giselle Barreto Diniz Rocha é licenciada em Educação Física. Universidade Federal de São João del-Rei. E-mail: xlbarreto@hotmail.com

Jéssica Faria Souto é bolsista de Iniciação Científica. Curso de Psicologia. E-mail: jefsouto@gmail.com

Larissa Medeiros Marinho dos Santos é professora Adjunta do Departamento e do Mestrado de Psicologia. Área Psicologia da Educação. E-mail: larissa@ufsj.edu.br 